\title{
The Significance of Scope 3 GHG Emissions in Construction Projects in Korea: Using EIA and LCA
}

\author{
Kyeong-Tae $\mathrm{Kim}^{1}$ and Ik $\mathrm{Kim}^{2, *(D)}$ \\ 1 Leo Engineering Firm, 42 Jangmi-ro, Bundang-gu, Seongnam-si 13496, Korea; kimkt701@naver.com \\ 2 SMaRT-Eco Consulting Firm, 630 Gaepo-ro, Gangnam-gu, Seoul 06338, Korea \\ * Correspondence: kohung@smart-eco.co.kr
}

Citation: Kim, K.-T.; Kim, I. The Significance of Scope 3 GHG Emissions in Construction Projects in Korea: Using EIA and LCA. Climate 2021, 9, 33. https://doi.org/10.3390/ cli9020033

Academic Editor: Chris Swanston

Received: 21 December 2020

Accepted: 17 February 2021

Published: 18 February 2021

Publisher's Note: MDPI stays neutral with regard to jurisdictional claims in published maps and institutional affiliations.

Copyright: (c) 2021 by the authors. Licensee MDPI, Basel, Switzerland. This article is an open access article distributed under the terms and conditions of the Creative Commons Attribution (CC BY) license (https:/ / creativecommons.org/licenses/by/ $4.0 /)$

\begin{abstract}
In Korea, a greenhouse gas (GHG) environmental impact assessment (EIA) has been conducting since 2012, which sets the evaluation procedures and methods for GHG items during the EIA. However, the current EIA on GHG emissions can support wrong decision-making because the evaluation does not consider Scope 3 GHG emissions. Accordingly, this study proposed the life cycle EIA (LCEIA) method to identify changes in GHG emissions that need to be managed by considering Scope 3 GHG emissions in construction projects. The LCEIA method incorporates life cycle $\mathrm{CO}_{2}\left(\mathrm{LCCO}_{2}\right)$ including Scope 1, Scope, and Scope 3 GHG emissions using the concept of life cycle assessment (LCA) into the scoping step of the EIA process. The case study was conducted using existing EIA on GHG emission and LCEIA methodology for a development project in Gwangyang City. Scenario 1 is defined as an approach that calculates GHG emissions using the existing EIA method, and scenario 2 is also defined as a process using the LCEIA method. Results reveal that Scenario 2, including Scope 3 GHG emissions, had 46.4-51.2\% more GHG emissions than Scenario 1. Sensitivity analysis for electricity and liquefied natural gas (LNG) density was also performed. Although the change in the carbon emission factor of electricity had a slightly sensitive effect on the research results, the LNG density was found to be less sensitive. This study believes the importance of switching to an EIA reflecting life cycle carbon dioxide $\left(\mathrm{LCCO}_{2}\right)$ to calculate the exact amount of GHG emissions for construction work.
\end{abstract}

Keywords: environmental impact assessment; life cycle assessment; Scope 3 GHG emissions; construction project; climate change

\section{Introduction}

Climate change is a huge environmental problem that humanity will face over the next decade [1]. In the Paris Agreement, governments agreed to keep global warming well below $2{ }^{\circ} \mathrm{C}$ and to try keeping it below $1.5^{\circ} \mathrm{C}$. The Intergovernmental Panel on Climate Change (IPCC) released a report in October 2018 on the $1.5^{\circ} \mathrm{C}$ target; it concluded that global emissions should reach net-zero around mid-century to give a reasonable chance of limiting warming to $1.5{ }^{\circ} \mathrm{C}$ [2]. In the Republic of Korea, policies are administered by the public sector, such as the central and local government, to calculate and reduce greenhouse gas (GHG) emissions from several sources. Typical examples are the GHG emission trading system, product carbon footprint labeling, and the private carbon point system [3-5].

Moreover, since 2012, the Korea Ministry of Environment has been conducting separate assessments by adding GHG emissions items to strategic environmental impact assessment (EIA) under the Environmental Impact Assessment Act to reduce GHG emissions caused by development projects [6]. EIA is a policy and management tool for both planning and decision-making. It assists to identify, predict, and evaluate the foreseeable environmental consequences of proposed development projects, plans, and policies [7]. The EIA policy was first introduced in 1969 based on the National Environmental Policy Act of the United States. In addition, it has been implemented based on the Environmental Conservation Act in Korea since 1981 [7]. 
Three scopes of GHG emissions can be considered when calculating GHG emissions for project levels. The direct and indirect GHG emission within the range that can be directly controlled by the project is called Scope 1 and Scope 2, respectively. Scope 1 GHG emissions are GHG emissions generated by the combustion of fuels on-site, and Scope 2 GHG emissions are GHG emissions emitted in the process of producing electricity and steam supplied on-site in upstream activities. Meanwhile, indirect GHG emissions in the range where direct control is not possible are called Scope 3 [8]. Scope 3 GHG emissions include GHG emissions generated in the manufacturing materials and fuels supplied on-site and GHG emissions emitted in operating and dismantling the building. Most projects make efforts to reduce GHG emissions from directly controllable scopes, but not from uncontrollable scopes. However, the effect of climate change is not a regional environmental problem, but a global environmental concern. Moreover, the conversion of the term climate change to the climate crisis has been proposed to raise awareness of the seriousness of climate change that causes continuous global damage [9]. Therefore, in addition to efforts to reduce GHG emissions in Scopes 1 and 2 that can be directly controlled by their own projects, countries are following the trend to manage Scope 3 GHG emissions that cannot be controlled [10].

Due to the seriousness of climate change, the EIA on GHG emission is being conducted in some developed countries, including the Republic of Korea. In Canada, the EIA has been carried out in accordance with the Canadian Environmental Assessment Act enacted in 2012. The EIA on GHG emissions calculates and evaluates the GHG emission of Scopes 1,2 , and 3 emitted in the entire life cycle of the project, including planning, construction, operation, modification, and completion stages [11]. The USA has also been conducting the EIA on GHG emissions under the National Environmental Policy Act and Guidance on Consideration of Greenhouse Gases. Similar to Canada's policy, the USA calculated and evaluated GHG emission for Scopes 1, 2, and 3 generated throughout the life cycle of the project [12]. The European Commission published the Guidance on Integrating Climate Change and Biodiversity into Environmental Impact Assessment (EIA) in 2013. It is recommended that the life cycle assessment (LCA) should be presented as an evaluation tool for GHG emissions [13]. Korea has also been operating the EIA scheme by using EIA guidelines on GHG emissions established the Environmental Impact Assessment Act in 2012. This scheme only includes GHG emission in scope 1 and scope 2, excluding scope 3. Accordingly, there is a lack of opportunities to sufficiently manage and reduce GHG emissions from construction projects through the EIA on GHG emissions. Therefore, the purpose of this study is to present the importance of calculating and managing scope 3 GHG emissions at the project level using a new method incorporating the concept of LCA into EIA for GHG emission in Korea.

\section{Materials and Methods}

\subsection{Existing Methodologies}

Madhu and Pauliuk (2019) conducted an environmental assessment of Masdar City, Abu Dubai using a methodology incorporating LCA into the EIA framework. In this paper, the degree of damage to human health, ecosystem, and resource due to construction work was analyzed. The features of this paper, taking into account the characteristics of the two methodologies, suggested that on-site effects apply EIA methodology and off-site effects apply LCA [14]. Rybaczewska-Blażejowska and Palekhov (2018) also proposed the EIA-LCA methodology that incorporates LCA into the EIA method to evaluate the environmental impacts from the industrial project. He did not incorporate LCA into the EIA framework but proposed the organizational LCA method as the EIA-LCA methodology [15]. This is a kind of LCA method for the organization, similar to ISO 14072:2014 and EU OEF (organization environmental footprint) methodology [16,17]. However, there was no study in previous studies on the development and application of integrated methodologies specialized to GHG emissions. In addition, there was no research on calculating and evaluating GHG emissions by dividing them into direct and indirect GHG emissions. 


\subsection{Proposal for Korea's EIA Method on GHG Emission}

The technical procedure of EIA followed EU Guidance on the preparation of the EIA report (EU EIA Guidance). The EIA procedures presented in the EU EIA Guidance include screening, scoping, EIA report, information and consultation, decision making and development consent, information on development consent, and monitoring [18]. The screening step is the first stage of the EIA process and determines the level of impact of the proposed project. The scoping step is EIA's second process of identifying the content and extent of the information to be submitted to the Competent Authority under the EIA process. The monitoring stage as the final step of the EIA process is to compare predicted and actual impacts. In general, the contents of EIA include air pollution, water pollution, biodiversity, noise and vibrations, and climate change effect, and so on. And the scope of GHG emissions of the EIA on GHG emissions in Korea includes Scope 1 and Scope 2 in accordance with the method of corporate GHG protocol published by WRI (World Resource Institute) and WBCSD (World Business Council for Sustainable Development) [8]. In the monitoring step of EIA on GHG emissions, the reduced GHG emissions by the project can be monitored.

This study selected only the effect of climate change among the various contents of environmental impacts and included three steps: the current step, construction step, and operation step from the scoping stage in accordance with the Korea EIA guideline on GHG emissions [19]. As shown in Figure 1, the extent of GHG emissions was also set at include life cycle carbon dioxide $\left(\mathrm{LCCO}_{2}\right)$ including Scope 1 , Scope 2, and Scope 3 using life cycle assessment concept. Typical LCA guidelines, such as ISO 14040, do not use the concepts of Scope 1, Scope 2, and Scope 3 to express the life cycle. Therefore, general LCA standards cannot be used as the LCA guide applied in this study [20]. So, this study applied the Product Life Cycle Accounting and Reporting Standard (product GHG protocol) as an LCA methodology to integrate into EIA similar to benchmark guidelines of Scope 1 and Scope 2 [21]. Also, the evaluation target of the proposed method is not a product, but a plan or project that affects the environment. The proposed method additionally reflected the requirements of ISO TS 14072, an organizational LCA standard [16]. The product has a clear function, but the organization does not have a clear function. So, it was evaluated using a declared unit rather than a functional unit. In this study, the proposed method was named the life cycle environmental impact assessment (LCEIA). The declared unit of LCEIA was defined as a project unit. A project's life cycle also included current, construction, operation steps. LCA items not mentioned above are set to comply with the requirements of ISO 14040. Thus, the proposed method was to compare with the existing EIA method on GHG emissions to identify the contribution to the omission of scope 3 GHG emissions at each step of the projects and propose an improved method.

\subsection{Selection of Target Project}

The area where the development project is being carried out is Seonghwal-doyee District, Gwangyang City, Jeollanam Province, South Korea. Gwangyang is a city located in the southeastern area of Jeollanam-do and has a large-scale steel industry complex and a representative global marine logistics port in Jeollanam-do. Gwangyang City has recently seen a significant increase in population inflow, including employees and tourists working in free economic zones. Gwangyang City decided to create an eco-friendly town, including residential and commercial land, to solve the housing problem. Figure 2 shows the location map of town development projects. The area of the development complex is $654,761 \mathrm{~m}^{2}$ and the project period is from 2009 to 2020 . The expected population is 8090 people, and the number of households consists of 3121. To create an eco-friendly town, Gwangyang City plans to create more green areas as a source of $\mathrm{CO}_{2}$ absorption than the current town. 


\section{Environmental Impact Assessment}

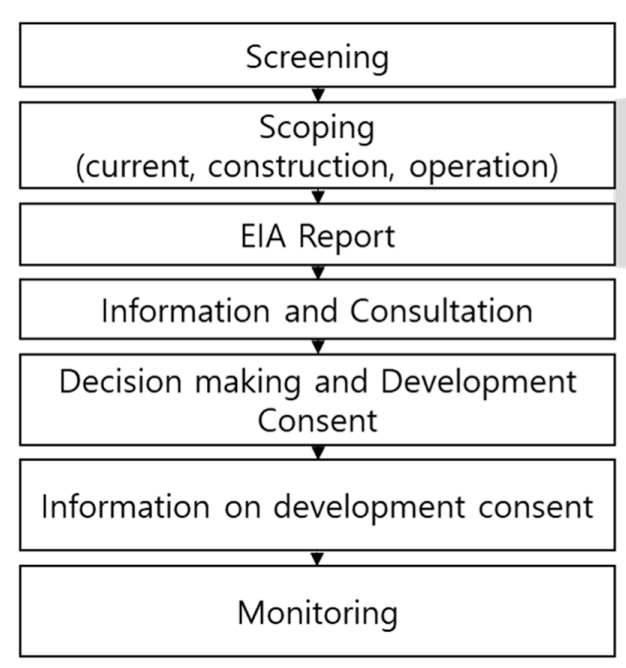

\section{Life Cycle Assessment}

Life Cycle $\mathrm{CO}_{2}\left(\mathrm{LCCO}_{2}\right)$

(Scope1 + Scope2 + Scope3)

Figure 1. Proposed method integrating the life cycle assessment (LCA) concept into the environmental impact assessment (EIA) framework.

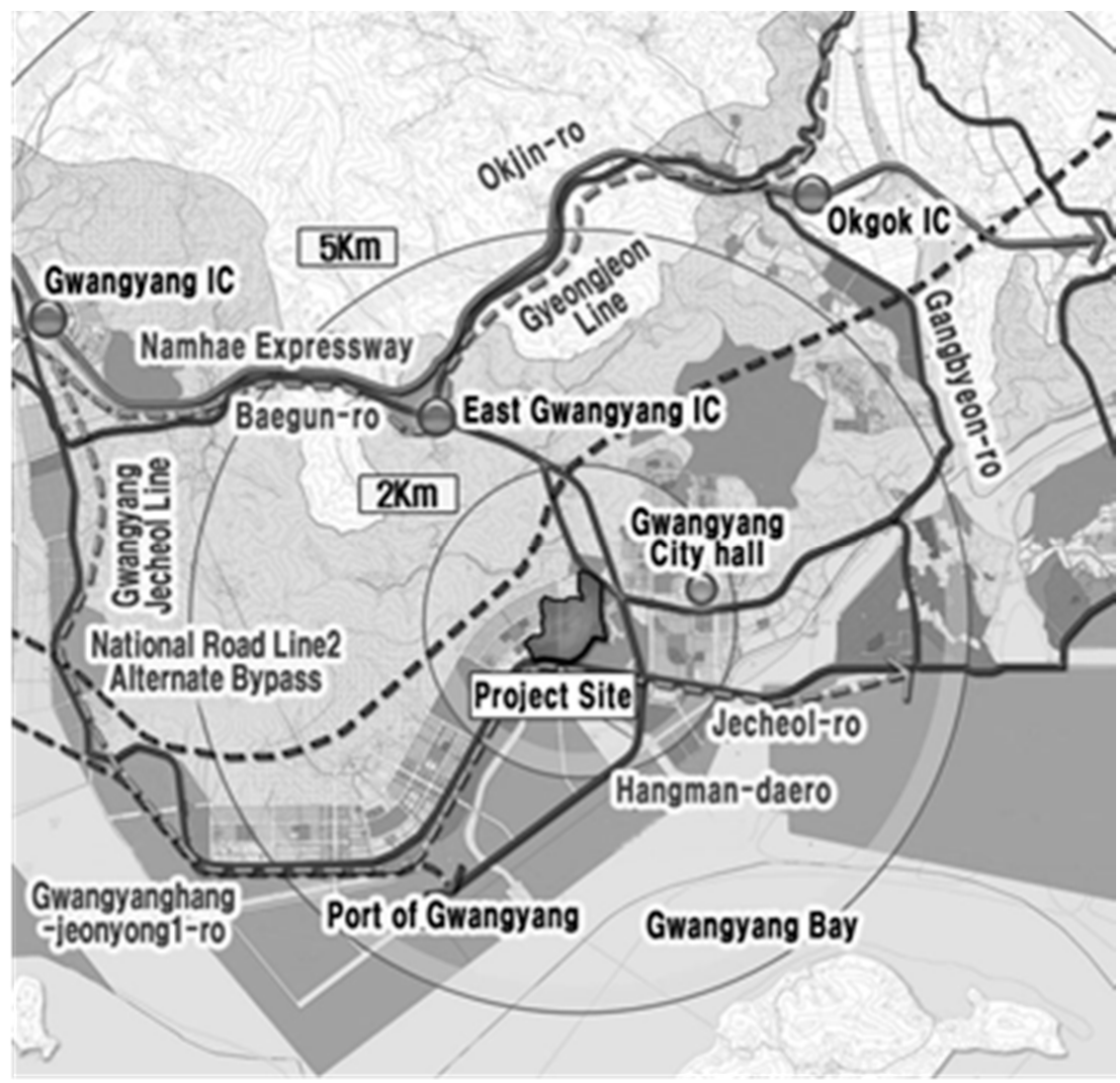

Figure 2. Location map of town development projects.

\subsection{EIA on GHG Emissions}

\subsubsection{Primary Data Collection}

GHG emissions for town development projects are calculated by dividing the emissions into the current step, construction step, and operation step. Here the operation step means the life of the town to be created by the development project. Table 1 shows a 
list of GHG emission and removal sources for each step. First, GHG removal sources of the current step are trees, land, and solar panels, and the sources of GHG emissions are electricity and gas fuel used at home. There are no removal sources in the construction step, and the GHG emission sources are electricity, fuel (diesel), and construction materials. The removal sources in the operation step are the same as the removal sources in the current step. GHG emission sources in the operation step include electricity and fuels such as liquefied natural gas (LNG), diesel, and gasoline.

Table 1. Inventories as a source of greenhouse gas (GHG) emissions and removals by three steps.

\begin{tabular}{|c|c|c|c|}
\hline Step & Division & Source & Unit \\
\hline \multirow{6}{*}{ Current } & \multirow{3}{*}{ GHG removal } & Tree & piece \\
\hline & & Land & $\mathrm{m}^{2}$ \\
\hline & & Photovoltaic & piece $/ 300 \mathrm{~W}$ \\
\hline & \multirow{3}{*}{ GHG emission } & Electricity & kWh/year \\
\hline & & Fuel (LNG) & $\mathrm{Nm}^{3} /$ year \\
\hline & & Waste & Ton/year \\
\hline \multirow{4}{*}{ Construction } & \multirow{4}{*}{ GHG emission } & Electricity & kWh/year \\
\hline & & Fuel (Diesel) & $\mathrm{L} /$ year \\
\hline & & Construction material & Ton/year \\
\hline & & Waste & Ton/year \\
\hline \multirow{8}{*}{ Operation } & \multirow{3}{*}{ GHG removal } & Tree & piece \\
\hline & & Land & $\mathrm{m}^{2}$ \\
\hline & & Photovoltaic & piece/300 W \\
\hline & \multirow{5}{*}{ GHG emission } & Electricity & kWh/year \\
\hline & & Fuel (LNG) & $\mathrm{Nm}^{3} /$ year \\
\hline & & Fuel (Diesel) & $\mathrm{L} /$ year \\
\hline & & Fuel (Gasoline) & $\mathrm{L} /$ year \\
\hline & & Waste & Ton/year \\
\hline
\end{tabular}

\subsubsection{Primary Data Calculation}

The calculation of GHG emissions and removals for each source at each step was conducted in two scenarios, namely, Scenarios 1 and 2. Scenario 1 includes Scope 1 and Scope 2 to calculate the amount of GHG emissions generated by each source. Scenario 1 is the scope of GHG calculation of the Korea Emission Trading System (ETS), which is the same as the scope of GHG calculation of EU ETS. Scenario 1 is the GHG calculation method recommended by Korea's EIA on GHG emissions. Meanwhile, Scenario 2 sets the calculating scope of GHG emissions to $\mathrm{LCCO}_{2}$. Scenario 2 is the scope of the LCA for products or organizations. Thus, the GHG calculation method based on EU ETS has been applied to estimate GHG emissions for projects or organizations. However, this study aims to analyze the feasibility of shifting to the LCA-based method instead of the EU ETS method. Table 2 shows the scopes of GHG emissions and removals by two scenarios in each source. In the case of trees, when Scenario 1 is applied, only $\mathrm{CO}_{2}$ is absorbed during the afforestation process, whereas when Scenario 2 is applied, $\mathrm{CO}_{2}$ absorption and Scope 3 sources such as pesticides and fertilizers are considered. Moreover, GHG emissions from construction materials used in large quantities in the construction process are included only in Scenario 2. 
Table 2. Scope of GHG emissions and removals by two scenarios in each source.

\begin{tabular}{|c|c|c|c|c|c|c|}
\hline \multirow{2}{*}{ Source } & \multicolumn{3}{|c|}{ Scenario 1} & \multicolumn{3}{|c|}{ Scenario 2} \\
\hline & Scope 1 & Scope 2 & Scope 3 & Scope 1 & Scope 2 & Scope 3 \\
\hline Tree & 0 & & & $\bigcirc$ & & $\bigcirc$ \\
\hline Land & 0 & & & 0 & & \\
\hline Photovoltaic & 0 & & & 0 & & 0 \\
\hline Electricity & & 0 & & & 0 & O \\
\hline Fuel (LNG) & 0 & & & 0 & & 0 \\
\hline Fuel (Diesel) & 0 & & & 0 & & O \\
\hline Fuel (Gasoline) & 0 & & & 0 & & 0 \\
\hline Construction material & & & & & & 0 \\
\hline Waste & & & & & & 0 \\
\hline
\end{tabular}

First, the amount of $\mathrm{CO}_{2}$ absorption by trees is obtained by multiplying the number by tree type and the absorption coefficient by tree type as shown in Equation (1) [19].

$$
U=\sum_{i=1}^{4}\left(N_{i} \times C F_{i}\right)
$$

where $U$ denotes GHG uptake, $N$ is the number of trees, $C F$ is the GHG emissions or absorption coefficient, $i$ includes arboreal hardwood, arboreal conifer, shrub hardwood, and shrub conifer. The GHG absorption coefficients of four types of trees are $28.5 \mathrm{~kg} \mathrm{CO}_{2} /$ tree.year, $7.4 \mathrm{~kg} \mathrm{CO}_{2} /$ tree.year, $0.6 \mathrm{~kg} \mathrm{CO}_{2} /$ tree.year, and $0.6 \mathrm{~kg} \mathrm{CO}_{2} /$ tree.year, respectively.

The storage of $\mathrm{CO}_{2}$ by the soil is calculated using Equation (2):

$$
S O C=\sum\left(S O C_{R E F_{c, s, i}} \times F_{L U_{c, s, i}} \times F_{M G_{c, s, i}} \times F_{I_{c, s, i}} \times A_{c, s, i}\right)
$$

where $S O C$ means soil organic carbon storage, $F$ is the variation coefficient of accumulation, and $A$ is the area of soil. Moreover, REF, $L U, M G$, and $I$ denote reference, land use, management system, and organic input, respectively. Finally, $c, s$, and $i$ denote the climate zone, type of soil, and the national system, respectively [20]. Table 3 shows the coefficient values for $\mathrm{CO}_{2}$ storage by the soil-applied in this study.

Table 3. Coefficient values for $\mathrm{CO}_{2}$ storage by the soil.

\begin{tabular}{ccccc}
\hline & $\begin{array}{c}\mathrm{SOC}_{\mathrm{REF}} \\
\text { (tonCO }\end{array}$ /ha) & $\mathbf{F}_{\mathrm{LU}}$ & $\mathbf{F}_{\text {MG }}$ & $\mathbf{F}_{\mathbf{I}}$ \\
\hline Forest & 88 & 1.00 & 1.14 & 1.11 \\
\hline Field & 88 & 0.69 & 1.00 & 1.00 \\
\hline Rice field & 88 & 1.10 & - & - \\
\hline Park & 88 & 1.00 & 1.14 & 1.11 \\
\hline
\end{tabular}

The scope 3 emissions generated during the production of construction materials, fuels, and electricity are calculated using Equation (3):

$$
C F_{i}=\sum_{j=1}^{n}\left(A_{i} \times E F_{i j}\right)
$$

where $C F$ denotes carbon footprint, $A$ is an activity as primary data such as electricity, $E F$ is scope 3 emission factor, $i$ is an emission source, $j$ is activity. 
In the current step, the amount of waste generated, electricity, and fuel consumption were calculated per capita based on the chapter of Gwangyang City, 2018 Jeollanam-do Statistical Yearbook [22]. In addition, the types of construction materials used were derived, and the amount of each material was calculated using the design in the construction step. Diesel consumption from using construction equipment was calculated by multiplying the number of units for each type of heavy equipment by its operation hours. The operation hours are assumed to be $8 \mathrm{~h} /$ day and 300 days/year. The amount of waste oil generated from heavy equipment is also the same as the method for calculating diesel consumption. In the operation step, waste generation and electricity consumption were calculated the same manner as in the current step.

\subsubsection{Applying Carbon Emission Factors (CEFs)}

The absorption coefficients in land and for each species were data presented in the EIA guide of the Ministry of Environment (MOE) [21]. Data for the following two types of CEFs of electricity were collected: CEF data published by the Korea GHG inventory and research center (Scenario 1) [23] and data published by the Korea Environmental Industry \& Technology Institute (KEITI) (Scenario 2) [24]. The former refers to GHG generated by power plants, and the latter refers to GHG generated in the life cycle of electricity.

\section{Results and Discussion}

\subsection{GHG EMISSIONs by Scenarios 1 and 2}

\subsubsection{Scenario 1}

Table 4 shows the GHG emission and absorption from different sources of three steps calculated using Scenario 1. The total GHG emission calculated from Scenario 1 was $87,527.6$ tonCO $\mathrm{C}_{2} \mathrm{e}$, including $\mathrm{CO}_{2}$ deposits in trees and soil, and $96,787.4$ tonCO $\mathrm{CO}_{2} \mathrm{e}$, excluding $\mathrm{CO}_{2}$ deposits. Thus, the amount of $\mathrm{CO}_{2}$ absorption and deposits in trees and soil was found to have been net eliminated, equivalent to $10.7 \%$ of total GHG emission. The current step accounted for $-5.7 \%$ of total GHG emissions, $2.0 \%$ of the construction step, and $103.7 \%$ of the operation step. In Scenario 1, the stage of the operation was found to have a dominant effect on climate change; moreover, the stage of construction contributed to a weak level. In particular, the amount of GHG emissions from electricity used during the operation step accounted for $69.1 \%$ of the total GHG emissions. The CEF of electricity used is $466 \mathrm{gCO}_{2} \mathrm{e} / \mathrm{kWh}$ [22].

Table 4. GHG emissions and stock by GHG sources of three steps (Scenario 1).

\begin{tabular}{|c|c|c|c|c|c|}
\hline Step & Source & Unit & GHG Emission & Stock & Sub-Total \\
\hline \multirow{7}{*}{ Current } & \multirow{2}{*}{ Tree } & tonCO $\mathrm{C}_{2} \mathrm{e} /$ year & -118.4 & & -118.4 \\
\hline & & ton $\mathrm{CO}_{2} \mathrm{e} /$ piece & & -1116.3 & -1116.3 \\
\hline & \multirow{2}{*}{ Land } & tonCO $\mathrm{C}_{2} \mathrm{e} /$ year & & & \\
\hline & & ton $\mathrm{CO}_{2} \mathrm{e} /$ land & & -4402.7 & -4402.7 \\
\hline & Electricity & tonCO $\mathrm{CO}_{2} \mathrm{e} /$ year & 189.4 & & 189.4 \\
\hline & LNG & ton $\mathrm{CO}_{2} \mathrm{e} /$ year & 460.3 & & 460.3 \\
\hline & Sub-total & tonCO $\mathrm{C}_{2} \mathrm{e} /$ year & $\begin{array}{c}531.3 \\
(0.6)\end{array}$ & $\begin{array}{l}-5519.0 \\
(-6.3 \%)\end{array}$ & $\begin{array}{l}-4987.7 \\
(-5.7 \%)\end{array}$ \\
\hline \multirow{3}{*}{ Construction } & Electricity & tonCO $\mathrm{C}_{2} \mathrm{e} /$ year & 2.8 & & 2.8 \\
\hline & Diesel & tonCO $\mathrm{C}_{2} \mathrm{e} /$ year & 1732.2 & & 1732.2 \\
\hline & Sub-total & tonCO $\mathrm{CO}_{2} \mathrm{e} /$ year & $\begin{array}{l}1735.0 \\
(2.0 \%)\end{array}$ & & $\begin{array}{l}1735.0 \\
(2.0 \%)\end{array}$ \\
\hline
\end{tabular}


Table 4. Cont.

\begin{tabular}{|c|c|c|c|c|c|}
\hline Step & Source & Unit & GHG Emission & Stock & Sub-Total \\
\hline \multirow{9}{*}{ Operation } & \multirow{2}{*}{ Tree } & ton $\mathrm{CO}_{2} \mathrm{e} /$ year & -141.7 & & -141.7 \\
\hline & & ton $\mathrm{CO}_{2} \mathrm{e} /$ piece & & -2331.5 & -2331.5 \\
\hline & \multirow{2}{*}{ Land } & tonCO $\mathrm{C}_{2} \mathrm{e} /$ year & & & \\
\hline & & tonCO $\mathrm{C}_{2} \mathrm{e} /$ land & & -1209.3 & -1209.3 \\
\hline & Electricity & tonCO $\mathrm{C}_{2} \mathrm{e} /$ year & $60,515.2$ & & $60,515.2$ \\
\hline & LNG & ton $\mathrm{CO}_{2} \mathrm{e} /$ year & $30,233.0$ & & $30,233.0$ \\
\hline & Diesel & ton $\mathrm{CO}_{2} \mathrm{e} /$ year & 678.6 & & 678.6 \\
\hline & Gasoline & ton $\mathrm{CO}_{2} \mathrm{e} /$ year & 3036.0 & & 3036.0 \\
\hline & Sub-total & ton $\mathrm{CO}_{2} \mathrm{e} /$ year & $\begin{array}{c}94,321.1 \\
(107.8 \%)\end{array}$ & $\begin{array}{l}-3540.8 \\
(-4.0 \%)\end{array}$ & $\begin{array}{c}90,780.3 \\
(103.7 \%)\end{array}$ \\
\hline \multicolumn{2}{|c|}{ Total } & ton $\mathrm{CO}_{2} \mathrm{e} /$ year & $\begin{array}{l}96,587.4 \\
(110.4 \%)\end{array}$ & $\begin{array}{c}-9059.8 \\
(-10.4 \%)\end{array}$ & $\begin{array}{l}87,527.6 \\
(100.0 \%)\end{array}$ \\
\hline
\end{tabular}

\subsubsection{Scenario 2}

Table 5 presents the GHG emissions and absorption from different sources of three steps, calculated using Scenario 2. Results in Table 5 reveal that the total GHG emissions, including and excluding the deposits, are $132,299.4$ tonCO $\mathrm{CO}_{2}$ and $141,359.2$ ton $\mathrm{CO}_{2}$, respectively. The current step absorbs GHGs equivalent to $3.6 \%$ of the total GHG emissions, the construction step emits GHG equivalent to $25.7 \%$ of the total GHG emissions, and the operation step also emits $77.9 \%$ of the total GHG emissions. In particular, the contributions to climate change in the construction step from Scenario 2 accounted for $25.7 \%$. In addition, the amount of GHG emissions generated by electricity use in the operation step was the most dominant at $48.6 \%$ of the total. Here, the CEF used to calculate GHG emissions from electricity use was $495 \mathrm{~g} \mathrm{CO}_{2} \mathrm{e} / \mathrm{kWh}$ in Scenario 2 [23].

Table 5. GHG emissions and stock by GHG sources of three steps (Scenario 2).

\begin{tabular}{|c|c|c|c|c|c|}
\hline Step & Inventory & Unit & GHG Emission & Stock & Sub-Total \\
\hline \multirow{8}{*}{ Current } & \multirow{2}{*}{ Tree } & ton $\mathrm{CO}_{2} \mathrm{e} /$ year & -118.4 & & -118.4 \\
\hline & & ton $\mathrm{CO}_{2} \mathrm{e} /$ piece & & -1116.3 & -1116.3 \\
\hline & \multirow{2}{*}{ Land } & tonCO $\mathrm{CO}_{2} \mathrm{e} /$ year & & & \\
\hline & & ton $\mathrm{CO}_{2} \mathrm{e} /$ land & & -4402.7 & -4402.7 \\
\hline & Electricity & tonCO $\mathrm{CO}_{2} \mathrm{e} /$ year & 201.2 & & 201.2 \\
\hline & LNG & ton $\mathrm{CO}_{2} \mathrm{e} /$ year & 564.0 & & 564.0 \\
\hline & $\begin{array}{l}\text { Waste } \\
\text { treatment }\end{array}$ & ton $\mathrm{CO}_{2} \mathrm{e} /$ year & 102.0 & & 102.0 \\
\hline & Sub-total & ton $\mathrm{CO}_{2} \mathrm{e} /$ year & $\begin{array}{c}748.8 \\
(0.6 \%)\end{array}$ & $\begin{array}{l}-5519.0 \\
(-4.2 \%) \\
\end{array}$ & $\begin{array}{l}-4770.2 \\
(-3.6 \%) \\
\end{array}$ \\
\hline \multirow{5}{*}{ Construction } & Electricity & ton $\mathrm{CO}_{2} \mathrm{e} /$ year & 3.0 & & 3.0 \\
\hline & Diesel & ton $\mathrm{CO}_{2} \mathrm{e} /$ year & 1743.0 & & 1743.0 \\
\hline & $\begin{array}{c}\text { Construction } \\
\text { materials }\end{array}$ & ton $\mathrm{CO}_{2} \mathrm{e} /$ year & $31,803.3$ & & $31,803.3$ \\
\hline & $\begin{array}{c}\text { Waste } \\
\text { treatment }\end{array}$ & ton $\mathrm{CO}_{2} \mathrm{e} /$ year & 485.6 & & 485.6 \\
\hline & Sub-total & ton $\mathrm{CO}_{2} \mathrm{e} /$ year & $\begin{array}{l}34,034.9 \\
(25.7 \%)\end{array}$ & & $\begin{array}{l}34,034.9 \\
(25.7 \%)\end{array}$ \\
\hline
\end{tabular}


Table 5. Cont.

\begin{tabular}{|c|c|c|c|c|c|}
\hline Step & Inventory & Unit & GHG Emission & Stock & Sub-Total \\
\hline \multirow{10}{*}{ Operation } & \multirow{2}{*}{ Tree } & ton $\mathrm{CO}_{2} \mathrm{e} /$ year & -141.7 & -2331.5 & -141.7 \\
\hline & & ton $\mathrm{CO}_{2} \mathrm{e} /$ piece & & -2331.5 & -2331.5 \\
\hline & \multirow{2}{*}{ Land } & tonCO $\mathrm{C}_{2} \mathrm{e} /$ year & & & \\
\hline & & tonCO $\mathrm{C}_{2} \mathrm{e} /$ land & & -1209.3 & -1209.3 \\
\hline & Electricity & ton $\mathrm{CO}_{2} \mathrm{e} /$ year & $64,290.0$ & & $64,290.0$ \\
\hline & LNG & tonCO $\mathrm{CO}_{2} \mathrm{e} /$ year & $36,788.0$ & & $36,788.0$ \\
\hline & Diesel & ton $\mathrm{CO}_{2} \mathrm{e} /$ year & 693.5 & & 693.5 \\
\hline & Gasoline & ton $\mathrm{CO}_{2} \mathrm{e} /$ year & 3109.5 & & 3109.5 \\
\hline & $\begin{array}{c}\text { Waste } \\
\text { treatment }\end{array}$ & tonCO $\mathrm{CO}_{2} \mathrm{e} /$ year & 1836.2 & & 1836.2 \\
\hline & Sub-total & ton $\mathrm{CO}_{2} \mathrm{e} /$ year & $\begin{array}{c}106,575.5 \\
(80.5 \%)\end{array}$ & $\begin{array}{l}-3540.8 \\
(-2.7 \%)\end{array}$ & $\begin{array}{c}103,034.7 \\
(77.9 \%)\end{array}$ \\
\hline \multicolumn{2}{|c|}{ Total } & tonCO $\mathrm{C}_{2} \mathrm{e} /$ year & $\begin{array}{l}141,359.2 \\
(106.8 \%)\end{array}$ & $\begin{array}{l}-9059.8 \\
(-6.8 \%)\end{array}$ & $\begin{array}{l}132,299.4 \\
(100.0 \%)\end{array}$ \\
\hline
\end{tabular}

\subsubsection{Comparison between Scenario 1 and Scenario 2}

Figure 3 compares the spectrum of GHG emissions from three steps in each Scenario. First, the GHG emission patterns of the three steps were similar in both Scenarios. There were more GHG emissions in Scenario 2 than in Scenario 1. In detail, GHG emissions using Scenario 2 at the current step was 40.9\% higher than Scenario 1, and Scenario 2 at the operation step was also $13.0 \%$ higher than Scenario 1. In particular, the amount of GHG emissions calculated by applying Scenario 2 in the construction step was $1861.7 \%$ higher than Scenario 1. GHG emissions from Scenario 2 in the current and operation steps are higher than in those from Scenario 1 because the CEF for electricity and fuel, such as LNG, diesel, and gasoline, applied in Scenario 2 includes $\mathrm{LCCO}_{2}$. In addition, GHG emissions produced by applying Scenario 2 in the construction step are 186.2 times higher than those produced by applying Scenario 1. This is because Scope 3 GHG emissions from the life cycle of construction materials are excluded in Scenario 1 but included in Scenario 2.

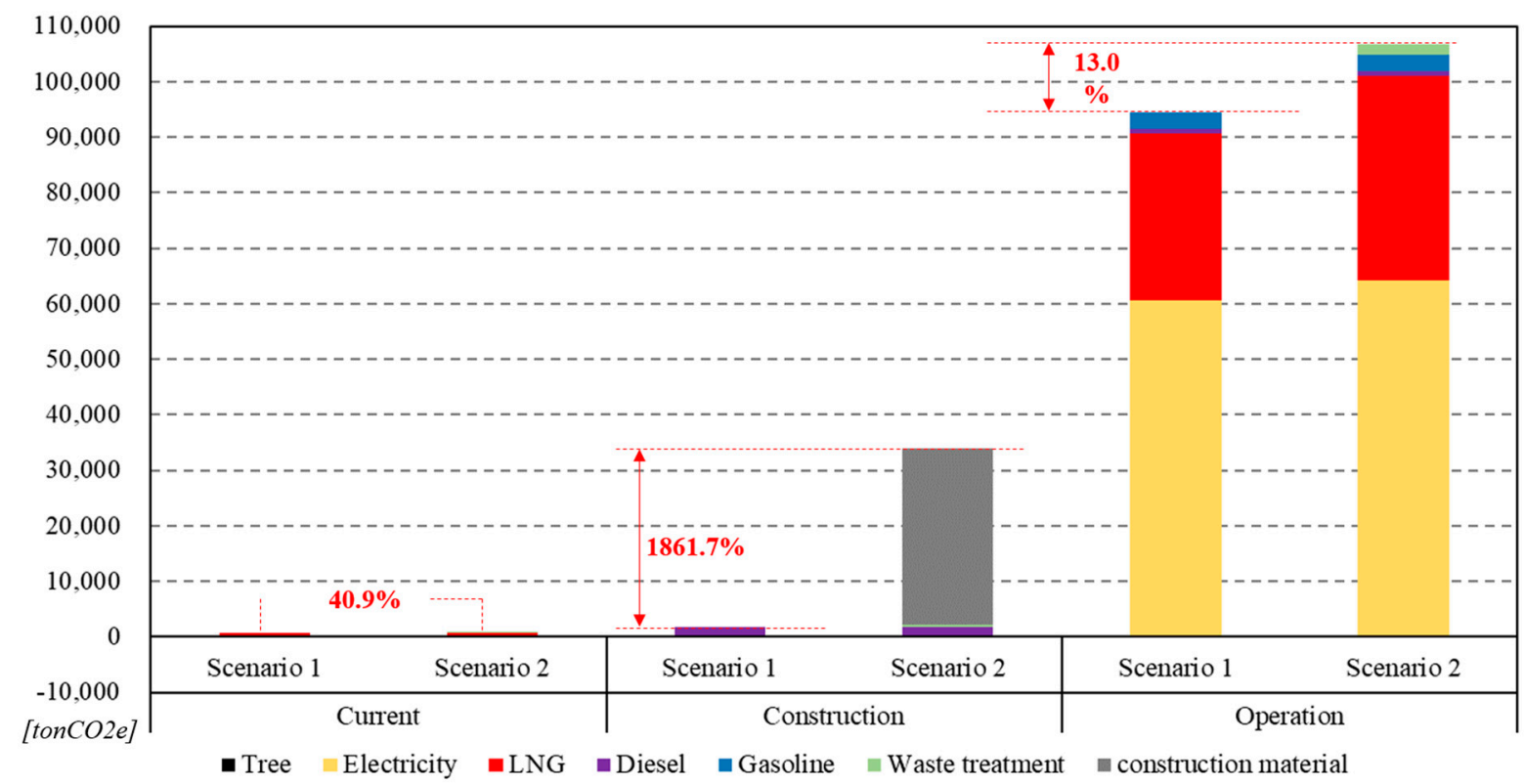

Figure 3. GHG spectrum of three steps of Scenarios 1 and 2. 
Table 6 presents the ratios between direct and indirect GHG emission sources emitted in the current, construction, and operation steps. Scenario 1 of Table 6 shows that indirect GHG emissions (Scope 2) from electricity use accounted for $62.9 \%$ of the total, followed by $37.1 \%$ of the net direct GHG emissions (Scope 1) from fuel use and $\mathrm{CO}_{2}$ absorption from trees and soil. In Scenario 2, Scope 2 emissions accounted for $42.9 \%$ of the total, followed by $31.7 \%$ of Scope 1 emissions. Meanwhile, the uncontrolled indirect emissions (Scope 3) from the production process of construction materials, fuels, and electricity in Scenarios 1 and 2 accounted for $0 \%$ and 31.7\% of the total GHG emissions, respectively. Thus, the implementation of the EIA on GHG emissions by applying Scenario 1 could omit $31.7 \%$ of GHG emissions. In response to climate change, the Korean government, industry, and private sector are making efforts to reduce GHG emissions. In this situation, the exclusion of the Scope 3 GHG emissions from building materials in Korea's EIA policy on GHG emissions could weaken the willingness of building materials producers to reduce GHG emissions.

Table 6. Comparison of GHG emissions by direct and indirect GHG emission sources.

\begin{tabular}{|c|c|c|c|c|c|c|c|c|c|c|}
\hline & \multicolumn{2}{|c|}{$\begin{array}{c}\text { Current } \\
\left(\text { ton } \mathrm{CO}_{2} \mathrm{e}\right)\end{array}$} & \multicolumn{2}{|c|}{$\begin{array}{l}\text { Construction } \\
\left.\text { (ton } \mathrm{CO}_{2} \mathrm{e}\right)\end{array}$} & \multicolumn{2}{|c|}{$\begin{array}{l}\text { Operation } \\
\left(\text { ton } \mathrm{CO}_{2} \mathrm{e}\right)\end{array}$} & \multicolumn{2}{|c|}{$\begin{array}{c}\text { Total } \\
\left(\text { ton } \mathrm{CO}_{2} \mathrm{e}\right)\end{array}$} & \multicolumn{2}{|c|}{$\begin{array}{c}\text { Ratio } \\
(\%)\end{array}$} \\
\hline & S1 & $\mathrm{S} 2$ & S1 & $\mathrm{S} 2$ & S1 & $\mathrm{S} 2$ & S1 & $\mathrm{S} 2$ & S1 & $\mathrm{S} 2$ \\
\hline Scope 1 & 341.9 & 341.9 & $33,805.9$ & $33,805.9$ & 1732.2 & 1732.2 & $35,880.0$ & $35,880.0$ & 37.1 & 25.4 \\
\hline Scope 2 & 189.4 & 189.4 & $60,515.2$ & $60,515.2$ & 2.8 & 2.8 & $60,707.4$ & $60,707.4$ & 62.9 & 42.9 \\
\hline Scope 3 & & 217.5 & & $12,254.4$ & & $32,299.9$ & & $44,771.8$ & & 31.7 \\
\hline
\end{tabular}

\subsection{Sensitivity Analysis}

\subsubsection{Key-issue Identification}

A sensitivity analysis was performed to increase the reliability of the research results. The sensitivity analysis was conducted on Scope 3 emission sources, which are the differences between Scenario 1 and Scenario 2. First, the different sources that emit Scope 3 GHG emissions were selected as the subjects for sensitivity analysis because the difference in method between Scenario 1 and Scenario 2 is whether to consider Scope 3 GHG emissions. Hence, trees and soil were excluded from the sources for sensitivity analysis. Next, the parameters that sensitively affect the changes in GHG emissions produced by applying Scenarios 1 and 2 were selected. Table 7 shows the GHG emissions and ratios of different sources for sensitivity analysis. As shown in Table 7, electricity and LNG accounted for $45.8 \%$ and $28.3 \%$ of the total GHG emissions, respectively. Therefore, this study selected electricity and LNG as the subjects for sensitivity analysis.

Table 7. GHG emissions and ratios (\%) of different sources for sensitivity analysis.

\begin{tabular}{cccccc}
\hline Source & Current & Construction & Operation & Sub-Total & Ratio (\%) \\
\hline LNG & $5.64 \times 10^{5}$ & - & $3.93 \times 10^{7}$ & $3.99 \times 10^{7}$ & $28.3 \%$ \\
\hline Electricity & $2.01 \times 10^{5}$ & $2.97 \times 10^{3}$ & $6.43 \times 10^{7}$ & $6.45 \times 10^{7}$ & $45.8 \%$ \\
\hline Fuel & - & $1.74 \times 10^{6}$ & $4.41 \times 10^{5}$ & $2.18 \times 10^{6}$ & $1.6 \%$ \\
\hline Aggregate & - & $7.95 \times 10^{5}$ & - & $7.95 \times 10^{5}$ & $0.6 \%$ \\
\hline $\begin{array}{c}\text { Ready-mixed } \\
\text { concrete }\end{array}$ & - & $1.05 \times 10^{7}$ & - & $1.05 \times 10^{7}$ & $7.4 \%$ \\
\hline Cement & - & $2.05 \times 10^{7}$ & - & $2.05 \times 10^{7}$ & $14.5 \%$ \\
\hline Steel frame & - & $8.57 \times 10^{4}$ & - & $8.57 \times 10^{4}$ & $0.1 \%$ \\
\hline Waste & $1.02 \times 10^{5}$ & $4.86 \times 10^{5}$ & $1.84 \times 10^{6}$ & $2.42 \times 10^{6}$ & $1.7 \%$ \\
\hline Sub-total & $8.67 \times 10^{5}$ & $3.40 \times 10^{7}$ & $1.06 \times 10^{8}$ & $1.41 \times 10^{8}$ & $100.0 \%$ \\
\hline
\end{tabular}




\subsubsection{Sensitivity Analysis of Electricity}

The sensitivity of research results was analyzed by changing the official sources of CEFs of electricity that directly affect its GHG emissions. The official CEFs for electricity, which were used as a variable for sensitivity analysis, used the CEFs applied in Scenarios 1 and 2, and the CEF of Korean electricity used in the French carbon certification system, $629 \mathrm{gCO}_{2} \mathrm{e} / \mathrm{kWh}$ [25]. Cases 1 and 2 used the CEFs of electricity by Scenarios 1 and 2, respectively. In Case 3, the French CEF of electricity was applied. In Cases 1 and 2, GHG emissions from electricity use accounted for $45.5 \%$ and $62.9 \%$ of the total GHG emissions, respectively. In addition, when the CEFs of electricity applied in Cases 1 and 2 were converted to the emission factor of Case 3, the GHG emissions increased by 17,459 and 21,246 tonCO $\mathrm{C}_{2} \mathrm{e}$, respectively. Table 8 shows the change in the proportion of GHG emissions by applying different variables. The amount of CEF of electricity changed from at least $45.6 \%$ to a maximum of $50.4 \%$. In addition, the proportion of GHG emissions by various sources except electricity has changed slightly. When the maximum GHG emission change of electricity was $4.8 \%$, the maximum GHG emission changes of LNG, fuel, aggregate, ready-mixed concrete, cement, steel frame, and waste were $2.5 \%, 0.2 \%, 0.1 \%, 0.8 \%, 1.7 \%$, $0.0 \%$, and $0.2 \%$, respectively. Therefore, this study determined that the change in CEF of electricity does not contribute significantly to changes in total GHG emissions.

Table 8. Changes in the ratio of GHG emissions by different variables.

\begin{tabular}{cccc}
\hline Source & Case 1 & Case 2 & Case 3 \\
\hline LNG & $28.2 \%$ & $29.0 \%$ & $25.7 \%$ \\
\hline Electricity & $45.6 \%$ & $44.1 \%$ & $50.4 \%$ \\
\hline Fuel & $1.5 \%$ & $1.6 \%$ & $1.4 \%$ \\
\hline Aggregate & $0.6 \%$ & $0.6 \%$ & $0.5 \%$ \\
\hline Ready-mixed concrete & $7.4 \%$ & $7.6 \%$ & $6.8 \%$ \\
\hline Cement & $14.5 \%$ & $14.9 \%$ & $13.2 \%$ \\
\hline Steel frame & $0.1 \%$ & $0.1 \%$ & $0.1 \%$ \\
\hline Waste & $1.7 \%$ & $1.8 \%$ & $1.6 \%$ \\
\hline
\end{tabular}

\subsubsection{Sensitivity Analysis on LNG}

The amount of consumption, CEF, and density are the variables that change GHG emissions generated by LNG combustion. Among these variables, the amount used is the actual primary data, and the CEF is the value calculated from the internationally accepted IPCC combustion formula [26]. Meanwhile, the density may vary from region to season. Therefore, this study selected the density as the subject to analyze the sensitivity of GHG emissions caused by LNG. Official data on the density of LNG were used as variables: $0.806 \mathrm{~kg} / \mathrm{Nm}^{3}$ presented by the KEITI, and $0.7767 \mathrm{~kg} / \mathrm{Nm}^{3}$ and $0.7861 \mathrm{~kg} / \mathrm{Nm}^{3}$ provided by the Korean LNG Bunkering Industry Association in 2010 and 2019 [24,27]. Here, the LNG densities applied in Cases 1,2 , and 3 were $0.806,0.7861$, and $0.7767 \mathrm{~kg} / \mathrm{Nm}^{3}$, respectively. Table 9 presents the sensitivity of total GHG emissions by changes in LNG density. When the LNG density changed from $100 \%$ to $99.37 \%$, the total GHG emissions changed from $100 \%$ to $99.86 \%$. Thus, we determined that changes in the LNG density have little effect on changes in GHG emissions.

Table 9. The sensitivity of total GHG emissions by changes in LNG density.

\begin{tabular}{cccc}
\hline & Case 1 & Case 2 & Case 3 \\
\hline LNG & $100.00 \%$ & $99.57 \%$ & $99.37 \%$ \\
\hline Total & $100.00 \%$ & $99.93 \%$ & $99.86 \%$ \\
\hline
\end{tabular}




\section{Conclusions}

The sustainable future of the Earth needs to predict environmental impacts by conducting EIA in various development projects. The EIA on GHG emissions also aims to prevent climate change in advance due to GHG generated during the development process. However, since the EIA on GHG emissions applied in Korea does not include all GHG emissions generated throughout the life cycle of the development projects, the results of the EIA on GHG emissions can support wrong decision-making. This study analyzed the differences in GHG emissions when Scenarios 1 and 2 were applied using examples of specific development projects. The case study also explained why the development project must consider $\mathrm{LCCO}_{2}$, including Scope 3 GHG emissions. Construction and building works account for $50 \%$ of the world's extraction resources, $35 \%$ of the EU's waste generation, and $5-12 \%$ of EU GHG emissions. Under these circumstances, the EIA on GHG emissions needs to calculate and evaluate GHG emissions using $\mathrm{LCCO}_{2}$ for construction projects. It is also important to use eco-friendly construction materials that emit less GHG emissions and contain less harmful substances in construction work.

Author Contributions: Conceptualization and method, I.K.; analysis and validation, K.-T.K.; resources and original draft preparation, K.-T.K.; writing and editing, I.K.; supervision and administration, I.K. All authors have read and agreed to the published version of the manuscript.

Funding: This research received no external funding.

Data Availability Statement: Not applicable.

Acknowledgments: This study was conducted with support from the Project on Development of Performance criteria of Ecological architecture based on the Environmental Product Declaration and Modularization construction technology of the Korea Agency for Infrastructure Technology Advancement (KAIA).

Conflicts of Interest: The authors declare no conflict of interest.

\section{References}

1. Iberdrola. The Big Global Environmental Issues We Need to Resolve by 2030. Available online: https:/ / www.iberdrola.com/ environment/most-important-environmental-issues (accessed on 15 January 2021).

2. Net Zero: Why is it Necessary? Energy \& Climate. Available online: https://eciu.net/analysis/briefings/net-zero/net-zero-why (accessed on 15 January 2021).

3. Korea GHG Emission Trading System. Available online: https://www.gihoo.or.kr/portal/kr/biz/kyoto.do (accessed on 15 January 2021).

4. Korea Carbon Footprint of Products (CFP) Certification System. Available online: http://www.epd.or.kr/eng/cfp/carbonIntro0 0.do (accessed on 19 November 2020).

5. Korea Carbon Point System. Available online: https://cpoint.or.kr/ (accessed on 19 November 2020).

6. Kim, K.T. A Study on Developing the Methodology for Climate \& Environmental Impact Assessment Using LCA Techniques. Ph.D. Thesis, Sejong University, Seoul, Korea, 2021.

7. Modak, P.; Biswas, A.K. Conducting Environmental Impact Assessment on Developing Countries; United Nations University: Tokyo, Japan, 1999.

8. Ranganathan, J.; Corbier, L.; Bhatia, P.; Schmitz, S.; Gage, P.; Oren, K. The Greenhouse Gas Protocol: A Corporate Accounting and Reporting Standard. In World Business Council for Sustainable Development and World Resource Institute; World Business Council for Sustainable Development: Geneva, Switzerland, 2004.

9. It's a Crisis, Not a Change: The Six Guardian Language Changes on Climate. Available online: https:/ /www.theguardian.com/ environment/2019/oct/16/guardian-language-changes-climate-environment (accessed on 15 January 2021).

10. Bhatia, P.; Cummis, C.; Brown, A.; Rich, D.; Draucker, L.; Lahd, H. The Greenhouse Gas Protocol: Corporate Value Chain (Scope 3) Accounting and Reporting Standard; World Business Council for Sustainable Development and World Resource Institute: Geneva, Switzerland, 2011; Available online: https:/ /ghgprotocol.org/sites/default/files/standards/Corporate-ValueChain-Accounting-Reporing-Standard_041613_2.pdf (accessed on 19 November 2020).

11. Alexander, G.; Bowen, J.; Church, I.; Burgess, S.; Calder, B.; Cleary, B.; Daly, C.; Dufresne, A.; Ehrlich, A.; Glen, M.; et al. Incorporating Climate Change Considerations in Environmental Assessment: General Guidance for Practitioners, the Federal-Provincial Territorial Committee on Climate Change and Environmental Assessment; Canadian Environmental Assessment Agency: Toronto, Canada, 2003. 
12. Geissler, G.; Köppel, J.; Odparlik, L.F. Addressing Greenhouse Gas Emissions in Environmental Impact Assessments-The Discursive Making of Guidance in the United States. UVP Rep. 2011, 25, 215-221.

13. McGuinn, J.; Hernandez, G.; Eales, R.; Sheate, W.; Baker, J.; Dusik, J.; Partidario, M.; Byron, H. Guidance on Integrating Climate Change and Biodiversity into Environmental Impact Assessment; European Union: Brussel, Belgium, 2013. Available online: http: / / ec.europa.eu/environment/eia/pdf/EIA\%20Guidance.pdf (accessed on 20 November 2020).

14. Madhu, K.; Pauliuk, S. Integrating Life Cycle Assessment into the Framework of Environmental Impact Assessment for Urban Systems: Framework and Case Study of Masdar City, Abu Dhabi. Environments 2019, 6, 105. [CrossRef]

15. Rybaczewska-Blażejowska, M.; Palekhov, D. Life Cycle Assessment (LCA) in Environmental Impact Assessment (EIA): Principles and practical implications for industrial projects. Management 2018, 22, 138-153. [CrossRef]

16. ISO. ISO TS 14072: Environmental Management-Life Cycle Assessment-Requirements and Guidelines for Organizational Life Cycle Assessment; International Organization for Standardization: Geneva, Switzerland, 2014.

17. Pelletier, N.; Allacker, K.; Manfredi, S.; Chomkhamsri, K.; Maia de Souza, D. Organizational Environmental Footprint Guide; European Commission Joint Research Centre: Brussel, Belgium, 2012.

18. Environmental Impact Assessment of Projects: Guidance on the preparation of the Environmental Impact Assessment Report; European Commission: Brussel, Belgium, 2017.

19. Environmsental Impact Assessment (EIA). Guide on Greenhouse Gas Items; Ministry of Environment: Sejong, Korea, 2015.

20. ISO. ISO 14040: Environmental Management-Life Cycle Assessment-Principles and Framework; ISO: Geneva, Switzerland, 1997.

21. Bhatia, P.; Cummis, C.; Brown, A.; Draucker, L.; Rich, D.; Lahd, H. GHG Protocol: Product Life Cycle Accounting and Reporting Standard. In World Resource Institute and World Business Council for Sustainable Development; World Business Council for Sustainable Development: Geneva, Switzerland, 2011.

22. 2018 Jeollanam-do Statistical Yearbook, Jeollanam-do, Muan. Korea. 2019. Available online: https://www.jeonnam.go.kr/M4 687 / boardView.do?seq=1890191\&infoReturn=\&menuId=jeonnam0508090000\&displayHeader=\&searchType=\&searchText= \&pageIndex=1\&boardId=M4687\&displayHeader= (accessed on 19 November 2020).

23. 2013 National GHG Emissions and Absorption Coefficients; Korea GHG Inventory and Research Center: Seoul, Korea, 2014.

24. Korea Environmental Product Declarations (EPD). Guide, Korea Environmental Industry and Technology Institute; Environmental Declaration Office: Seoul, Korea, 2018.

25. Specifications of the Call for Tenders Relating to the Construction and Operation of Installations for the Production of Electricity from Solar Photovoltaic or Wind Energy Located in the Mainland; The French Energy Regulatory Commission: Paris, French, 2018.

26. Gómez, D.; Watterson, J.D.; Americano, B.B.; Ha, C. 2006 IPCC Guidelines for National Greenhouse Gas Inventories: Chapter 2 Stationary Combustion. In Intergovernmental Panel on Climate Change; World Business Council for Sustainable Development: Geneva, Switzerland, 2006.

27. Korea LNG Bunkering Industry Association: Energy Conversion. Available online: http://www.kolbia.org/contents/sub02_03.php? unit=2 (accessed on 19 November 2020). 